\title{
Hepatic sclerosed hemangioma with special attention to diffusion-weighted magnetic resonance imaging
}

\author{
Tatsunori Miyata', Toru Beppu ${ }^{1,2}$, Kunitaka Kuramoto ${ }^{1,2}$, Shigeki Nakagawa', Katsunori Imai', Daisuke Hashimoto ',
} Tomohiro Namimoto ${ }^{3}$, Yo-ichi Yamashita', Akira Chikamoto ${ }^{1}$, Yasuyuki Yamashita ${ }^{3}$ and Hideo Baba ${ }^{1 *}$ (D)

\begin{abstract}
Background: A hepatic sclerosed hemangioma $(\mathrm{HSH})$ is a very rare benign liver tumor. The correct preoperative diagnosis of HSH is very difficult because its features of imaging are similar to those of intrahepatic cholangiocarcinoma or colorectal liver metastasis.

Case presentation: We experienced five patients who were diagnosed histologically with HSH. The preoperative diagnoses were HSH in two patients, cavernous hemangioma in one, intrahepatic cholangiocarcinoma in one, and colorectal liver metastasis in one. All patients were treated with hepatectomy (one laparoscopic and four laparotomies), and the diagnosis was completed by histological investigation of the resected specimen. In particular, we investigated the apparent diffusion coefficient (ADC) mean value using diffusion-weighted sequences of magnetic resonance imaging (DW-MRI). The average of the ADC mean ( $A D C_{\text {mean }}$ ) value of $\mathrm{HSH}$ was $1.94 \times 10^{-3} \mathrm{~mm}^{2} / \mathrm{s}$ (range $1.73-2$. $10 \times 10^{-3} \mathrm{~mm}^{2} / \mathrm{s}$ ), which was higher than the value of common malignant liver tumors. Interestingly, the ADC mean values were almost the same between the degenerate $\left(1.90 \pm 0.17 \times 10^{-3} \mathrm{~mm}^{2} / \mathrm{s}\right)$ and the non-degenerate areas $(1.95$ $\left.\pm 0.26 \times 10^{-3} \mathrm{~mm}^{2} / \mathrm{s}\right)$ in $\mathrm{HSH}$.
\end{abstract}

Conclusions: The $A D C_{\text {mean }}$ value seemed to be quite useful to preoperatively distinguish $\mathrm{HSH}$ from other malignant liver tumors.

Keywords: Sclerosed hemangioma, Diffusion-weighted sequences of magnetic resonance imaging, Apparent diffusion coefficient

\section{Background}

A hepatic sclerosed hemangioma (HSH) is a very rare benign subtype of hepatic hemangioma and is detected in only $0.2 \%$ of cases in a study of 1000 consecutive necropsies [1]. Since its image features resemble those of hepatic malignancies such as intrahepatic cholangiocarcinoma (ICC) [2] or colorectal liver metastasis (CRLM) [3], HSH is frequently suspected to be hepatic malignancies that need to be resected. Overall, HSH is often diagnosed correctly after resection. To avoid an unnecessary operation, accurate preoperative diagnosis of $\mathrm{HSH}$ is required.

\footnotetext{
* Correspondence: hdobaba@kumamoto-u.ac.jp

${ }^{1}$ Department of Gastroenterological Surgery, Graduate School of Life

Sciences, Kumamoto University, 1-1-1, Honjo, Chuo-ku, Kumamoto 860-0811,

Japan

Full list of author information is available at the end of the article
}

One of the most effective methods for the differential diagnosis of liver tumors is magnetic resonance imaging (MRI). Conventional and diffusion-weighted MRI (DW-MRI) are effective techniques for the characterization of focal solid hepatic lesions [4]. In addition, the apparent diffusion coefficient (ADC) value in DW-MRI has been useful for distinguishing malignant from benign liver tumors [4-6]. To the best of our knowledge, this is the first study about the utility of the ADC mean $\left(\mathrm{ADC}_{\text {mean }}\right)$ value in multiple patients with $\mathrm{HSH}$. We herein would like to demonstrate detailed imaging findings of five cases along with literature reviews.

\section{Cases presentation \\ Patients and imaging methods}

From July 2009 to November 2016, five patients in our institutions were histologically diagnosed using a resected 
specimen with $\mathrm{HSH}$, which were confirmed by pathologists. The patients underwent imaging examinations, including ultrasonography (US), contrast-enhanced computed tomography (CT), gadolinium-ethoxybenzyldiethylenetriamine pentaacetic acid (Gd-EOB-DTPA)-enhanced MRI, and ${ }^{18} \mathrm{~F}$-fluorodeoxyglucose positronemission tomography (FDG-PET). We considered the part with the contrast effect in $\mathrm{CT}$ as non-degenerative site, and the other part as degenerative site. To obtain an accurate preoperative diagnosis, we additionally performed DWMRI with respiratory triggering using $b$ values of 0 and $800 \mathrm{~s} / \mathrm{mm}^{2}$, and ADC maps were generated using $b$ values of 0 and $800 \mathrm{~s} / \mathrm{mm}^{2}$ for calculation of the ADC value. Of the five patients, four were evaluated using a 3.0-Tesla whole-body MRI scanner and one patient was evaluated using a 1.5-Tesla whole-body MRI scanner; studies have demonstrated similar ADC values between the 1.5- and 3.0-Tesla scanners $[7,8]$. The $\mathrm{ADC}_{\text {mean }}$ value was calculated by taking the average of the six areas of ADC values, which were randomly selected at the degenerative (three areas) and non-degenerative areas (three areas) of each $\mathrm{HSH}$. Similarly, we separately evaluated the $\mathrm{ADC}_{\text {mean }}$ values in the degenerative and non-degenerative areas. For the comparative analysis, we also evaluated the $\mathrm{ADC}_{\text {mean }}$ values in the degenerative and non-degenerative areas of the adenocarcinoma with necrosis in the liver. We randomly selected six ICC patients and four CRLM patients from our database of patients with liver tumors. They were also diagnosed histologically using the resected specimen. The radiological data was independently assessed by two radiologists. We also retrospectively investigated the preoperative blood test data, imaging data, and pathological findings.

\section{Statistical analysis}

Comparisons between the $\mathrm{ADC}_{\text {mean }}$ values of the degenerative and non-degenerative areas were examined using Student's $t$ test. The results with two-tailed values of $P<0.05$ were considered to be statistically significant. All statistical analyses were performed using JMP software (Version 12; SAS Institute, Cary, NC, USA).

\section{Patient characteristics}

The clinical characteristics of the patients with $\mathrm{HSH}$ were summarized in Table 1 . Four male and one female were included, and their mean age was 60 years (range 34-79 years). Hepatitis B virus surface antigen (HBs-Ag) was positive in two patients, and hepatitis $\mathrm{C}$ virus antibody (HCV-Ab) was negative in all patients. All patients' carcinoembryonic antigen and carbohydrate antigen 19-9 were within their normal ranges. The most predicted preoperative diagnoses were $\mathrm{HSH}$ in two patients, cavernous hemangioma in one, ICC in one, and CRLM in one.

\section{US, CT, and PET imaging features}

$\mathrm{HSH}$ presented with different echogenicity based on the degree of regenerative tissue in the ultrasound images. The features of HSH on CT were summarized in Table 2. All tumors were solitary with lobulated shapes, and the tumor sizes varied from 6 to $148 \mathrm{~mm}$. Three patients had simultaneous hemangiomas, and three patients showed contractive changes on the tumor surface. All tumors had low densities on plain CT images. Two patients had ring enhancements, and two patients had peripheral nodular enhancements in the arterial phase. Two tumors had a low-density mass, and three had a progressive centripetal fill-in pattern from the portal to venous phase in the CT images (as seen in cases 3 and 5 shown in Figs. 1a and 2a). Three patients underwent FDG-PET; however, no FDG accumulation was observed in the $\mathrm{HSH}$.

\section{MRI features}

The features of HSH on MRI were summarized in Table 3. All tumors had no fatty tissue and were hypointense on T1-weighted images and hyperintense on T2-weighted images, as seen in case 3 (Fig. 1b). Three tumors showed ring enhancements, and two tumors showed peripheral

Table 1 Characteristics of five patients with hepatic sclerosed hemangioma

\begin{tabular}{|c|c|c|c|c|c|c|c|c|c|c|}
\hline Case & Age & Gender & Etiology & $\begin{array}{l}\text { CA19-9 } \\
(\mathrm{U} / \mathrm{ml})\end{array}$ & CEA (ng/ml) & Comorbidity & Location & Size $(\mathrm{mm})$ & $\begin{array}{l}\text { Preoperative } \\
\text { diagnosis }\end{array}$ & Operation \\
\hline Case 1 & 79 & M & None & 8.5 & 1.0 & None & $\mathrm{S} 5 / 6$ & 43 & ICC & Anatomical resection \\
\hline Case 2 & 34 & $\mathrm{~F}$ & None & 16 & 1.1 & None & Whole right lobe & 148 & Hemangioma & $\begin{array}{l}\text { Extended hemi-right } \\
\text { hepatectomy }\end{array}$ \\
\hline Case 3 & 70 & M & HBV & 6.4 & 2.5 & $\begin{array}{l}\text { Colon } \\
\text { cancer }\end{array}$ & S6 & 15 & CRLM & $\begin{array}{l}\text { Laparoscopic partial } \\
\text { hepatectomy }\end{array}$ \\
\hline Case 4 & 63 & M & HBV & 12.7 & 1.7 & HCC (S4) & S7 & 6 & $\begin{array}{l}\text { Sclerosed } \\
\text { hemangioma }\end{array}$ & Partial hepatectomy \\
\hline Case 5 & 54 & M & None & 9.1 & 1.4 & None & S8 & 27 & $\begin{array}{l}\text { Sclerosed } \\
\text { hemangioma }\end{array}$ & Partial hepatectomy \\
\hline
\end{tabular}


Table 2 Computed tomography $(C T)$ features of five patients with hepatic sclerosed hemangioma

\begin{tabular}{|c|c|c|c|c|c|c|c|}
\hline \multirow[b]{2}{*}{ Case } & \multirow[b]{2}{*}{$\begin{array}{l}\text { Simultaneous } \\
\text { hemangioma }\end{array}$} & \multirow[b]{2}{*}{$\begin{array}{l}\text { Capsular } \\
\text { retraction }\end{array}$} & \multirow[b]{2}{*}{$\begin{array}{l}\text { Arterioportal } \\
\text { shunt }\end{array}$} & \multirow[b]{2}{*}{ Plain CT } & \multicolumn{3}{|l|}{ Dynamic CT } \\
\hline & & & & & Arterial phase & Portal phase & Venous phase \\
\hline Case 1 & + & - & + & Low & Ring enhancement & $\begin{array}{l}\text { Progressive } \\
\text { centripetal fill-in }\end{array}$ & $\begin{array}{l}\text { Progressive } \\
\text { centripetal fill-in }\end{array}$ \\
\hline Case 2 & - & - & - & Low & $\begin{array}{l}\text { Peripheral nodular } \\
\text { enhancement }\end{array}$ & $\begin{array}{l}\text { Progressive } \\
\text { centripetal fill-in }\end{array}$ & $\begin{array}{l}\text { Progressive } \\
\text { centripetal fill-in }\end{array}$ \\
\hline Case 3 & + & + & - & Low & Ring enhancement & Low & Low \\
\hline Case 4 & - & + & + & Low & Low & Low & Low \\
\hline Case 5 & + & + & + & Low & $\begin{array}{l}\text { Peripheral nodular } \\
\text { enhancement }\end{array}$ & $\begin{array}{l}\text { Progressive } \\
\text { centripetal fill-in }\end{array}$ & Low \\
\hline
\end{tabular}

nodular enhancements in the arterial phase. Three tumors showed progressive centripetal fill-in patterns during the late phase. All tumors were described as defects in the hepatocyte phase on MRI, as seen in case 5 (Fig. 2b). The average $\mathrm{ADC}_{\text {mean }}$ value for the five cases was $1.94 \times 10^{-3} \mathrm{~mm}^{2} / \mathrm{s}$ (range $1.72-2.09 \times 10^{-3} \mathrm{~mm}^{2} / \mathrm{s}$ ). The average ( \pm standard deviation) values of the $\mathrm{ADC}_{\text {mean }}$ were approximately the same between the degenerate $\left(1.90 \pm 0.17 \times 10^{-3} \mathrm{~mm}^{2} / \mathrm{s}\right)$ and non-degenerate areas $\left(1.95 \pm 0.26 \times 10^{-3} \mathrm{~mm}^{2} / \mathrm{s} ; p=0.615\right)$ (Fig. 3). However, there were significant differences in the $\mathrm{ADC}_{\text {mean }}$ values between the enhanced $\left(1.90 \pm 0.25 \times 10^{-3} \mathrm{~mm}^{2} / \mathrm{s}\right)$ and non-enhanced areas $\left(1.18 \pm 0.25 \times 10^{-3} \mathrm{~mm}^{2} / \mathrm{s}\right)$ of ICC and CRLM in the early phase of MRI $(p<0.0001)$ (Fig. 4). Their background factors were listed in Additional file 1: Table S1.

\section{Operation and pathological examination}

Although three patients were diagnosed with suspicious benign tumors, we could not deny their possibility of malignancy. Furthermore, patients desired to receive hepatectomy to obtain pathological diagnosis. We underwent laparoscopic hepatectomy for one (case 3) and hepatectomy with laparotomy for the others (Table 1). Histologically, there were many small vessels with fibrous replacement and hyalinization in all cases. All patients could discharge without any complications.

\section{Discussion}

Herein, we described the clinical, pathological, and imaging features of five patients with $\mathrm{HSH}$. Interestingly, the $\mathrm{ADC}_{\text {mean }}$ values had a different pattern between $\mathrm{HSH}$ and malignant liver metastases; however, the $\mathrm{ADC}_{\text {mean }}$ values were similar in the degenerate and nondegenerate areas of HSH. To the best of our knowledge, the current study is the first report to mention the differences of $\mathrm{ADC}_{\text {mean }}$ values between the degenerate and non-degenerate areas in HSH.

Cavernous hemangioma is the most common hepatic vascular tumor in adults [9], while $\mathrm{HSH}$ is an extremely
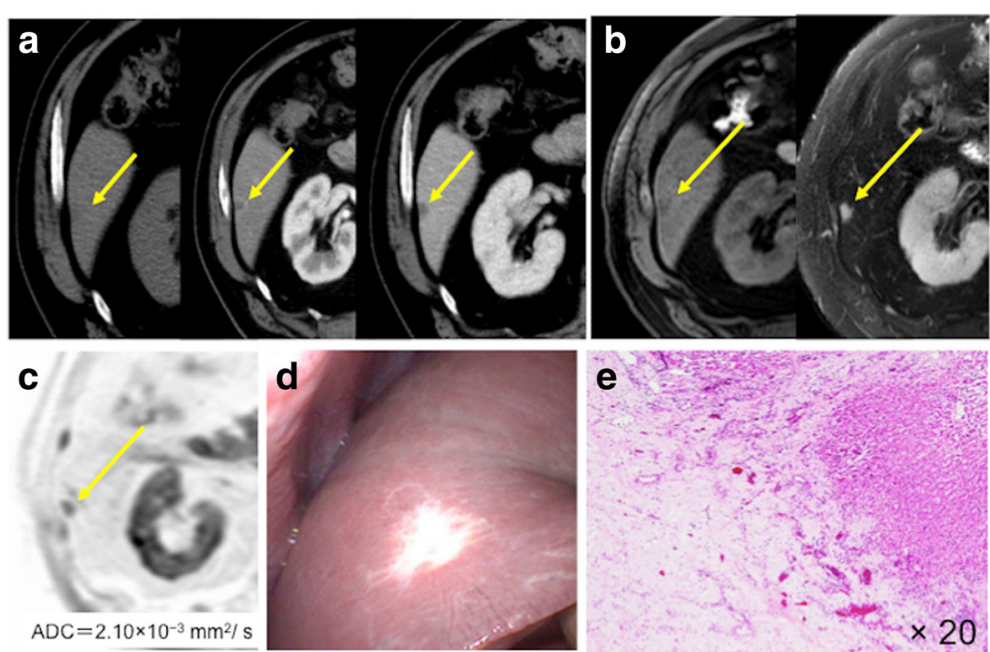

Fig. 1 The tumor showed ring enhancement in the arterial phase and low-density mass in the portal phase (a) in a CT image. MRI showed that $\mathrm{HSH}$ is a hypointense mass on a fat-suppressed T1-weighted image and a hyperintense mass on a T2-weighted MRI scan (b). The ADC mean value of the mass was $2.10 \times 10^{-3} \mathrm{~mm}^{2} / \mathrm{s}$ on DW-MRI (c). A whitish tumor was shown on the liver surface and capsular retraction was identified (d). Histologically, there were many small vessels with fibrous replacement and hyalinization (e) 


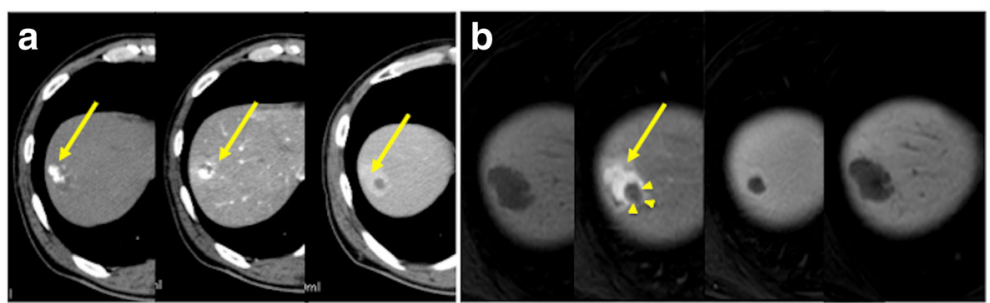

C

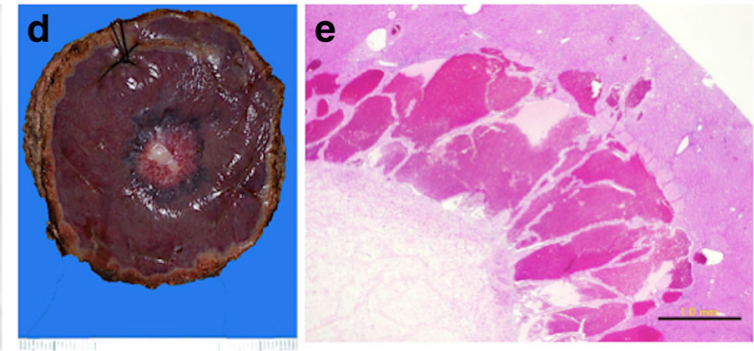

Fig. 2 The tumor was seen as a mass with peripheral nodular enhancement in the arterial phase and progressive centripetal fill-in in the portal phase of CT imaging (a). MRI showed that HSH was a hypointense mass on a fat-suppressed T1-weighted image and a mass with peripheral nodular enhancement in the early phase. In the late phase, the tumor was an iso-hypointense mass and filling defect in the hepatocyte phase of dynamic MRI. We considered the part with the contrast effect in CT or MRI as non-degenerative site (arrow) and the other part as degenerative site (arrow head). (b). The ADC mean value of the mass was $2.09 \times 10^{-3} \mathrm{~mm}^{2} / \mathrm{s}$ on DW-MRI (c). The whitish part was shown within the hemangioma-like tumor on the liver surface and capsular retraction was identified (d). Histologically, there were many small vessels with fibrous replacement and hyalinization. The scale bar shows $1.0 \mathrm{~mm}(\mathbf{e})$

rare liver tumor [1]. HSH has various degenerative changes such as extensive fibrosis with subsequent hyalinization, marked narrowing or obliteration of the vascular spaces, and hemorrhage or sclerosis [10]. Makhlouf and Ishak compared the findings of HSH and cavernous hemangioma in terms of pathology. Compared with cavernous hemangioma, HSH contained abundance of collagenous tissue and elastic fibers around and between small sclerotic vessels. In addition, vascular endothelial markers (i.e., CD31, CD34, FVIII-R Ag) were weaker, suggesting there was senescence in blood vessels [11]. However, the mechanism for degenerative changes in $\mathrm{HSH}$ and the origin of HSH remain unclear at present. $\mathrm{HSH}$ itself is benign tumor; therefore, it is considered good to follow up without resection as long as there are no symptoms.

Cavernous hemangioma is usually found as a single mass tumor of five $\mathrm{cm}$ or less [12]. It is contrasted from the periphery in dynamic $\mathrm{CT}$, the contrast effect gradually spreads to the center (progressive centripetal fillin), and furthermore, the contrast effect prolonging from the equilibrium phase to the delay phase (prolonged enhancement) is recognized [13]. On the other hand, HSH has several different imaging features. Doyle et al. reported that the findings of geographic pattern, capsular retraction, decreased size over time, and loss of previously seen regions of enhancement suggested $\mathrm{HSH}$. Moreover, they also showed a difference in the transient hepatic attenuation, rim enhancement, and nodular regions of intense enhancement, as seen in typical hemangiomas [14]. In our cases, all tumors showed ring enhancement or peripheral nodular enhancement in the arterial phase and two cases were described as having progressive centripetal fill-in from the portal to the venous phase in CT images. Therefore, all cases had previous features of HSH or cavernous hemangioma; however, we could not deny the possibility of a malignancy because ICC and CRLM have several similar features on imaging $[2,3]$. In particular, in case 3 , the patient was simultaneously diagnosed with colon cancer, which contributed to a misdiagnosis of the liver tumor as CRLM. Sakamoto et al. reported that liver hemangioma of $5 \mathrm{~cm}$ or less was frequently diagnosed as malignant tumor [15], and even in our cases, four cases were $\mathrm{HSH}$ of $5 \mathrm{~cm}$ or less. Thus, it is quite difficult to perform accurate diagnosis only with dynamic CT or MRI.

The $\mathrm{ADC}_{\text {mean }}$ value on DW-MRI may be useful for distinguishing $\mathrm{HSH}$ from other malignant liver tumors. In malignant tumors, we often observed tissue invasion and a cancerous environment with increased cellularity and enlarged cells, which contributed to a reduction in the extracellular space. In addition, cancer cells harbored more hyperchromatin and exhibited a high nucleus-tocytoplasm ratio, limiting the diffusion of water molecules in intracellular spaces $[4,5]$. These histopathological characteristics result in a decrease in the $\mathrm{ADC}_{\text {mean }}$ value. Bruegel et al. showed that the $\mathrm{ADC}_{\text {mean }}$ value was $1.22 \times 10^{-3} \mathrm{~mm}^{2} / \mathrm{s}$ for metastatic liver tumors and $1.92 \times 10^{-3} \mathrm{~mm}^{2} / \mathrm{s}$ for hemangiomas [16]. Namimoto et 


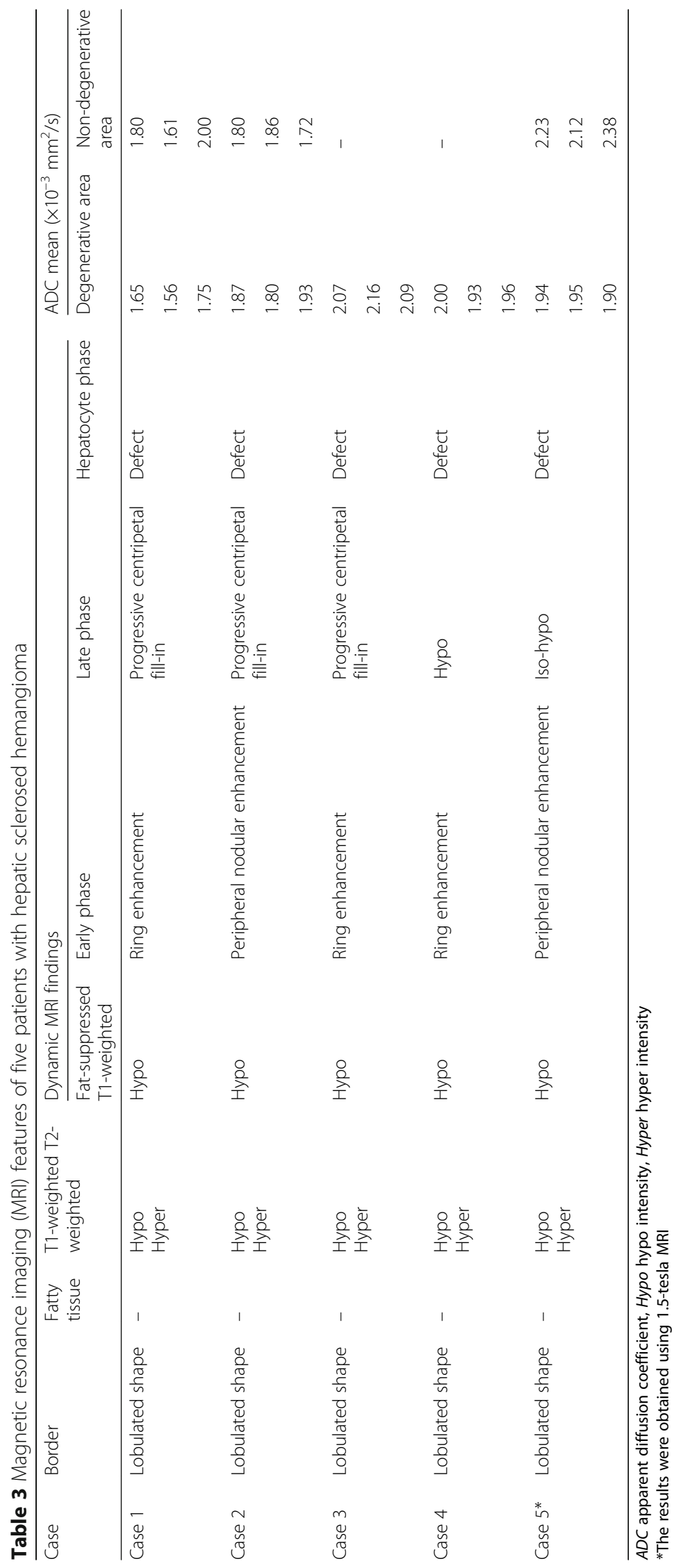




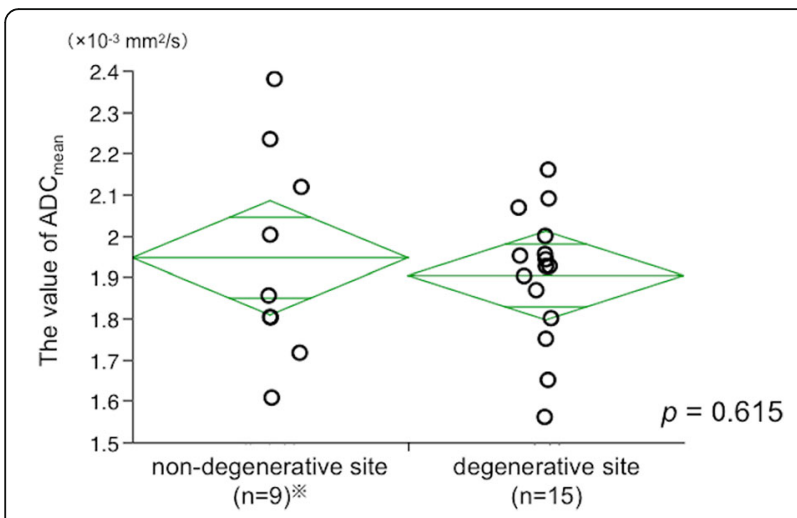

Fig. 3 The average values of $A D C_{\text {mean }}$ were almost the same between the degenerate $\left(1.90 \pm 0.17 \times 10^{-3} \mathrm{~mm}^{2} / \mathrm{s}\right)$ and the non-degenerate areas $\left(1.95 \pm 0.26 \times 10^{-3} \mathrm{~mm}^{2} / \mathrm{s}\right)(t$ test, $p=0.615)$. *Two cases were very small tumors; therefore, we could not determine the $A D C_{\text {mean }}$ value in the non-degenerative area

al. also showed that the $\mathrm{ADC}_{\text {mean }}$ values of the hepatocellular carcinoma, metastases, ICC, and hemangiomas were $1.15 \pm 0.21 \times 10^{-3}, 1.23 \pm 0.32 \times 10^{-3}, 1.52 \pm 0.26 \times$ $10^{-3}$, and $2.09 \pm 0.43 \times 10^{-3} \mathrm{~mm}^{2} / \mathrm{s}$, respectively [5]. In addition, Hida et al. showed that the $\mathrm{ADC}_{\text {mean }}$ value of $\mathrm{HSH}$ was $2.01 \times 10^{-3} \mathrm{~mm}^{2} / \mathrm{s}$ [17]. Therefore, these authors suggested that the $\mathrm{ADC}_{\text {mean }}$ values of $\mathrm{HSH}$ and cavernous hemangioma (approximately $2.00 \times 10^{-3} \mathrm{~mm}^{2} / \mathrm{s}$ ) tended to be higher than those of malignant liver tumors. In our five cases, the average $\mathrm{ADC}_{\text {mean }}$ value of the five HSHs was $1.94 \times 10 \times 10^{-3} \mathrm{~mm}^{2} / \mathrm{s}$. This result support previous reports.

Interestingly, our results also showed the $\mathrm{ADC}_{\text {mean }}$ values were almost of the same degree and higher than malignant tumors between the degenerate and the nondegenerate areas, suggesting that the non-degenerate areas had a similar cellular density compared to the

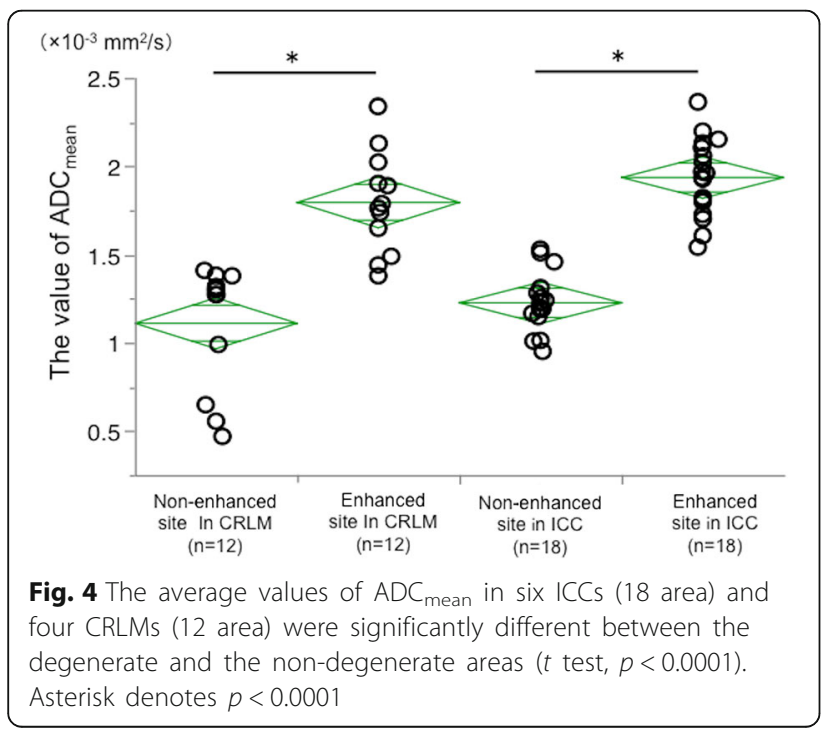

degenerate areas in HSH. In fact, in the pathological findings, although the fibrous tissue of the degenerate area was abundant, the cell density in the degenerate area was not very high. In addition, it is recognized that the size of HSH decreases; it is rare to limit the extracellular space. On the other hand, in the case of a malignant tumor, tissue invasion and cancer nests exhibiting increased cellularity and enlarged cells. This reduced the size of the extracellular space, and the cancer cells harbored more organelles, enlarged nuclei, and hyperchromatism and exhibited a high nuclear-to-cytoplasmic ratio, limiting the diffusion of water molecules in intracellular spaces [5]. Therefore, there is a difference in the ADC value between the contrast part and the noncontrast part in malignant tumor. Thus, our data suggested that it was possible to distinguish between $\mathrm{HSH}$ and malignant liver tumors by calculating the $\mathrm{ADC}_{\text {mean }}$ values in tumor and by comparing both the degenerate and non-degenerate areas in $\mathrm{HSH}$.

\section{Conclusions}

Using the $\mathrm{ADC}_{\text {mean }}$ value on DW-MRI may be an effective method for distinguishing HSHs from other malignant liver tumors, especially in liver adenocarcinomas with degenerative areas. Further investigation of a large number of HSH patients will be needed.

\section{Additional file}

Additional file 1: Table S1. Characteristics of patients with ICC or CRLM. (DOCX $142 \mathrm{~kb})$

\section{Abbreviations}

ADC: Apparent diffusion coefficient; CRLM: Colorectal liver metastasis; CT: Computed tomography; FDG-PET: Fluorodeoxyglucose positron-emission tomography; Gd-EOB-DTPA: Gadolinium-ethoxybenzyl-diethylenetriamine pentaacetic acid; HSH: Hepatic sclerosed hemangioma; ICC: Intrahepatic cholangiocarcinoma; MRI: Magnetic resonance imaging; US: Ultrasonography

Funding

This study was not funded.

\section{Authors' contributions}

TM described and designed the article. TB and TN edited the article. YY and $\mathrm{HB}$ supervised the edition of the manuscript. Other remaining co-authors collected the data and discussed the content of the manuscript. All authors read and approved the final manuscript.

Ethics approval and consent to participate

Written informed consent was obtained from the patient for publication of this case report and any accompanying images.

\section{Competing interests}

The authors declare that they have no competing interests.

\section{Publisher's Note}

Springer Nature remains neutral with regard to jurisdictional claims in published maps and institutional affiliations. 


\section{Author details}

'Department of Gastroenterological Surgery, Graduate School of Life Sciences, Kumamoto University, 1-1-1, Honjo, Chuo-ku, Kumamoto 860-0811, Japan. ${ }^{2}$ Department of Surgery, Yamaga City Medical Center, 511, Yamaga, Kumamoto 861-0593, Japan. ${ }^{3}$ Department of Diagnostic Radiology, Faculty of Life Sciences, Kumamoto University, 1-1-1, Honjo, Chuo-ku, Kumamoto 860-0811, Japan.

Received: 22 September 2017 Accepted: 26 December 2017

Published online: 03 January 2018

\section{References}

1. Berry CL. Solitary "necrotic nodule" of the liver: a probable pathogenesis. J Clin Pathol. 1985;38:1278-80.

2. Miyamoto S, Oshita A, Daimaru Y, Sasaki M, Ohdan H, Nakamitsu A. Hepatic Sclerosed Hemangioma: a case report and review of the literature. BMC Surg. 2015;15:45

3. Yamashita Y, Shimada M, Taguchi K, Gion T, Hasegawa H, Utsunomiya T, et al. Hepatic sclerosing hemangioma mimicking a metastatic liver tumor: report of a case. Surg Today. 2000;30:849-52.

4. Taouli B, Koh DM. Diffusion-weighted MR imaging of the liver. Radiology. 2010;254:47-66.

5. Namimoto T, Yamashita Y, Sumi S, Tang Y, Takahashi M. Focal liver masses: characterization with diffusion-weighted echo-planar MR imaging. Radiology. 1997;204:739-44.

6. Onur MR, Cicekci M, Kayali A, Poyraz AK, Kocakoc E. The role of ADC measurement in differential diagnosis of focal hepatic lesions. Eur J Radiol. 2012:81:e171-6.

7. Dale BM, Braithwaite AC, Boll DT, Merkle EM. Field strength and diffusion encoding technique affect the apparent diffusion coefficient measurements in diffusion-weighted imaging of the abdomen. Investig Radiol. 2010;45:104-8.

8. Rosenkrantz AB, Oei M, Babb JS, Niver BE, Taouli B. Diffusion-weighted imaging of the abdomen at 3.0 Tesla: image quality and apparent diffusion coefficient reproducibility compared with 1.5 Tesla. J Magn Reson Imaging. 2011:33:128-35.

9. Jeong MG, Yu JS, Kim KW. Hepatic cavernous hemangioma: temporal peritumoral enhancement during multiphase dynamic MR imaging. Radiology. 2000;216:692-7.

10. Cheng HC, Tsai SH, Chiang JH, Chang CY. Hyalinized liver hemangioma mimicking malignant tumor at MR imaging. AJR Am J Roentgenol. 1995, 165:1016-7.

11. Makhlouf HR, Ishak KG. Sclerosed hemangioma and sclerosing cavernous hemangioma of the liver: a comparative clinicopathologic and immunohistochemical study with emphasis on the role of mast cells in their histogenesis. Liver. 2002;22:70-8.

12. Tait N, Richardson AJ, Muguti G, Little JM. Hepatic cavernous haemangioma: a 10 year review. Aust N Z J Surg. 1992;62:521-4.

13. Barnett PH, Zerhouni EA, White RI Jr, Siegelman SS. Computed tomography in the diagnosis of cavernous hemangioma of the liver. AJR Am J Roentgenol. 1980;134:439-47.

14. Doyle DJ, Khalili K, Guindi M, Atri M. Imaging features of sclerosed hemangioma. AJR Am J Roentgenol. 2007;189:67-72.

15. Sakamoto Y, Kokudo N, Watadani T, Shibahara J, Yamamoto M, Yamaue H. Proposal of size-based surgical indication criteria for liver hemangioma based on a nationwide survey in Japan. J Hepatobiliary Pancreat Sci. 2017;24:417-25.

16. Bruegel M, Holzapfel K, Gaa J, Woertler K, Waldt S, Kiefer B, et al. Characterization of focal liver lesions by ADC measurements using a respiratory triggered diffusion-weighted single-shot echo-planar MR imaging technique. Eur Radiol. 2008;18:477-85.

17. Hida T, Nishie A, Tajima T, Taketomi A, Aishima S, Honda H. Sclerosed hemangioma of the liver: possible diagnostic value of diffusion-weighted magnetic resonance imaging. Jpn J Radiol. 2010;28:235-8.

\section{Submit your manuscript to a SpringerOpen ${ }^{\mathcal{O}}$ journal and benefit from:}

- Convenient online submission

- Rigorous peer review

- Open access: articles freely available online

- High visibility within the field

- Retaining the copyright to your article 